\title{
Non-vitamin K Antagonist Oral Anticoagulants in Adult Congenital Heart Disease: A Single Center Study
}

Pedro Brás ( $\square$ pedrobras3@gmail.com )

Hospital de Santa Marta https://orcid.org/0000-0002-9970-7828

Tânia Branco Mano

Hospital de Santa Marta

Tiago Rito

Hospital de Santa Marta

Alexandra Castelo

Hospital de Santa Marta

Vera Ferreira

Hospital de Santa Marta

Ana Agapito

Hospital de Santa Marta

Rui Cruz Ferreira

Hospital de Santa Marta

Fátima Pinto

Hospital de Santa Marta

Lídia Sousa

Hospital de Santa Marta

\section{Research Article}

Keywords: Adult congenital heart disease, NOACs, Non-vitamin K antagonist oral anticoagulants, antithrombotic therapy

Posted Date: February 10th, 2022

DOI: https://doi.org/10.21203/rs.3.rs-1330770/v1

License: @ (i) This work is licensed under a Creative Commons Attribution 4.0 International License. Read Full License 


\section{Abstract}

Purpose: Non-vitamin K antagonist anticoagulants (NOACs) prescription is increasing in adults with congenital heart disease (ACHD), however data on efficacy and safety in ACHD is unclear, particularly in patients $(P)$ with complex CHD. The aim of the study was to review the safety and efficacy of in various types of ACHD.

Methods: Evaluation of ACHD P started on NOAC therapy from 2014 to 2020, followed-up for bleeding or thromboembolic events (TE) and mortality. $\mathrm{CHA}_{2} \mathrm{DS}_{2}$-VASc and HASBLED scores were calculated and risk factors for bleeding were identified.

Results: 93 ACHD P, mean age $52 \pm 15$ years, $58 \%$ female, $55.9 \%$ moderate $\mathrm{CHD}$ and $23.7 \%$ with severe $\mathrm{CHD}\left(3.2 \%\right.$ Fontan). $66 \%$ of $\mathrm{P}$ had a $\mathrm{CHA} \mathrm{DSS}_{2}-\mathrm{VASc}$ score $\geq 2$ and $82 \%$ HASBLED score $\leq 2$.

In a mean follow-up of $41 \pm 21$ months (400.4 patient-years), there were TE in 2P ( 1 splenic infarction and 1 pulmonary embolism). The annual risk for TE was $0.49 \% /$ patient/year. The cardiovascular mortality was $2 \%$ and all-cause mortality $5 \%$, however with no relation to TE or bleeding events.

$6 \mathrm{P}(6.5 \%)$ suffered a minor and $3 \mathrm{P}(3.2 \%)$ suffered a major bleeding, a median time of 12 (IQR 15) months after starting NOAC therapy. The annual risk for bleeding was $2.2 \%$ /patient/year.

Renal disease (HR 14.6 [95\% Cl 1.23-73.6], p=0.033 and the HAS-BLED score were predictors of major (adjusted HR 6.97 [95\% Cl 1.69-28.78], p=0.007) and minor (adjusted HR 3.80 [95\% Cl 1.48-9.78], p=0.006) bleeding complications.

Conclusion: NOACs are a safe and effective option for selected ACHD P, although bleeding complications were not negligible

\subsection{Introduction}

In the past decade, non-vitamin K antagonist oral anticoagulants (NOACs) have emerged as an alternative to vitamin K antagonists (VKAs) with clearly demonstrated beneficial effect in patients with acquired heart disease [1]. While there has been emerging data on the increasing use of NOACs in adult congenital heart disease (ACHD)[2] the question remains whether NOACs can be used effectively and safely in this heterogenous and complex population

NOACs provide a convenient alternative to VKAs, bypassing the need for monitoring or frequent dose adjustments, with less food and drug interactions [3-4], improving quality of life[5] and potentially reducing risk of intracranial bleeding and stroke [6]. Moreover, ACHD patients are a generally younger population with an active lifestyle aiming to minimize medical intervention.

Atrial arrhythmias are common in this population, as well as anatomical subtracts that predispose to thrombotic events, particularly in severe ACHD. CHD severity is a known predictor of thromboembolism, as well as an increased CHA囚DS囚-VASc score. On other hand, while major bleeding events are not dependent on ACHD severity [7], the HAS-BLED has shown a strong correlation with major bleeding. Notably, patients with Fontan circulation appear to be at higher risk of both thromboembolic and bleeding events, including patients with total cavopulmonary connection (TCPC) [5-8].

While there have been no randomized large scale studies in this population, the NOTE registry[9] and a recent meta-analysis [8] showed an annual event rate of both thromboembolism and major bleeding comparable to data from acquired heart disease. However, worrisome conflicting results were advanced revealing worse outcomes for ACHD patients treated with NOAC compared to those with VKAs, including higher mortality rates and major cardiovascular events [2].

The European Society of Cardiology (ESC) 2020 ACHD guidelines refer that NOACs appear similarly safe and effective as VKAs (in the absence of contraindications as mechanical valves or severe mitral valve stenosis) and recommend the use of anticoagulation in the context of $A F /$ intra-atrial re-entrant tachycardia in patients with moderate or severe ACHD, while still suggesting the use of CHA囚DS区-VASc and HAS-BLED scores in simple defects [10]. The 2018 ACC/AHA ACHD guidelines also recommend the selective use of NOACs in subgroups of patients with an individual approach regarding the dose and type of NOACs [11]. VKAs are currently recommended over NOACs in patients with a mechanical prosthetic valve, significant atrioventricular valve stenosis, intracardiac thrombus, intracardiac shunts or within three months of cardiac surgery [12]. Additional studies are needed to confirm NOAC efficacy in complex ACHD, especially those with a Fontan-type circulation.

Our aim was to review the prescription of NOACs in a single center tertiary ACHD clinic, assessing its safety and efficacy in this population. We aspired to evaluate whether bleeding and thromboembolic events under NOAC therapy in this ACHD cohort were infrequent, as described in large scale registries [9] or, on the other hand, if they were common and associated with worse outcomes, as shown in recent studies [2].

\subsection{Methods}

This study enrolled adult patients (older than 18 years) with ACHD, in a single tertiary center, that were started on NOAC therapy between 2014 and 2020 . The study population was divided according to CHD complexity (mild, moderate or severe, according to the Bethesda classification [10]) and main diagnosis or pathophysiological status: tetralogy of Fallot (TOF), transposition of the great arteries (TGA), single ventricle physiology (including patients with Fontan-type circulation), systemic-pulmonary shunts (atrial and/or ventricular or arterial), left ventricular outflow tract disease (BAV, aortic and subaortic stenosis), aortic coarctation, right ventricular outflow tract disease (pulmonary stenosis or atresia) and pulmonary vascular disease.

A retrospective follow-up evaluation was undertaken, regarding bleeding events (minor or major), thromboembolic events, all-cause mortality and cardiovascular mortality. 
Demographic data and laboratory tests were reviewed and CHA囚DS®-VASc and HAS-BLED scores were calculated for each patient.

Oral anticoagulation indication, NOAC prescription and dosage, as well as dose adjustments, switch to VKA and anticoagulation suspension (for clinical reasons) were registered.

Furthermore, possible risk factors for higher bleeding risk were evaluated as predictors of bleeding events in ACHD, including age, gender, ACHD severity, renal impairment, CHA囚DS®-VASc and HAS-BLED scores.

Major bleeding was defined as intracranial bleeding or a life-threatening haemorrhage that caused substantial hemodynamic compromise requiring treatment (according to the GUSTO bleeding classification). Thromboembolic events were specified as ischemic stroke (defined as de novo focal neurologic deficits without bleeding signs in cranial computorized tomography [CT]), extracranial systemic embolism (defined as signs or symptoms of affected organ embolism, confirmed with CT) or pulmonary embolism (diagnosed with CT angiography). The investigation followed the principles outlined in the Declaration of Helsinki.

\subsubsection{Statistical analysis}

Statistical analysis was performed using the Statistical Package for the Social Sciences, V.23.0 for Windows (SPSS). Point estimates and 95\% Cl are presented for all mean estimates.

Descriptive statistics are presented as absolute frequency (number) and relative frequency (percentage) for categorical variables and as the mean (and standard deviation) for continuous variables. The Kolmogorov-Smirnov test was used to test normality assumptions.

Correlations between categorical variables were assessed with the Chi-square test and correlations between continuous variables were assessed with the Student's T test.

The correlation between risk factors for bleeding and bleeding events were calculated with univariable Cox regressions. Subsequently multivariable analyses, adjusted for potential confounders, were performed. Whenever statistical hypothesis testing was used, a significance level of a $=5 \%$ was considered.

\subsection{Results}

Ninety-five patients adults with CHD were included, $58 \%$ female, mean age $52 \pm 15$ years, $19(20.4 \%)$ with mild CHD, 52 (55.9\%) with moderate CHD and 22 (23.7\%) with complex CHD, according to the Bethesda classification [10]. Patient characteristics are shown in Table 1. 
Table 1

Characteristics of patients with adult congenital heart disease under NOAC therapy

\begin{tabular}{|c|c|c|c|c|}
\hline CHD severity & Mild & Moderate & Severe & Total \\
\hline$N(\%)$ & $19(20)$ & $52(56)$ & $22(24)$ & $93(100)$ \\
\hline Female gender, $\mathrm{n}(\%)$ & $12(63)$ & $28(54)$ & $14(64)$ & $62(58)$ \\
\hline Age (years) & $57 \pm 14$ & $54 \pm 14$ & $44 \pm 15$ & $52 \pm 15$ \\
\hline $\mathrm{BMI}\left(\mathrm{kg} / \mathrm{m}^{2}\right)$ & $27.6 \pm 5.4$ & $25.7 \pm 4.7$ & $23.3 \pm 3.7$ & $25.6 \pm 4.8$ \\
\hline Hypertension, n (\%) & $8(42)$ & $14(27)$ & $0(0)$ & $22(24)$ \\
\hline Diabetes, $\mathrm{n}(\%)$ & $2(11)$ & $4(8)$ & $0(0)$ & $6(7)$ \\
\hline Dyslipidaemia, n (\%) & $6(32)$ & $12(23)$ & $2(9)$ & $20(22)$ \\
\hline Smoker, n (\%) & $3(16)$ & $7(13)$ & $0(0)$ & $10(11)$ \\
\hline Atrial fibrillation, $\mathrm{n}(\%)$ & $18(95)$ & $38(73)$ & $10(45)$ & $66(71)$ \\
\hline Atrial flutter/atrial tachycardia, n (\%) & $4(21)$ & $15(29)$ & $2(9)$ & $21(23)$ \\
\hline Pacemaker, n (\%) & $2(11)$ & $9(17)$ & $2(9)$ & $13(14)$ \\
\hline ICD, n (\%) & $0(0)$ & $6(12)$ & $3(14)$ & $9(10)$ \\
\hline Anemia, n (\%) & $4(21)$ & $16(31)$ & $4(18)$ & $24(26)$ \\
\hline Mean serum creatinine (mL/min) & $1.05 \pm 0.34$ & $0.86 \pm 0.18$ & $0.85 \pm 0.23$ & $0.89 \pm 0.24$ \\
\hline Thrombocytopenia, n (\%) & $1(5)$ & $1(2)$ & $2(9)$ & $4(4)$ \\
\hline Severe pulmonary hypertension, $\mathrm{n}(\%)$ & $0(0)$ & $0(0)$ & $7(32)$ & $7(8)$ \\
\hline Previous stroke, n (\%) & $0(0)$ & $4(8)$ & $4(18)$ & $8(9)$ \\
\hline Concomitant APT, n (\%) & $0(0)$ & $4(8)$ & $0(0)$ & $4(4)$ \\
\hline CHAXDS\&-VASc, median (IQR) & $2(1.5-4)$ & $2(2-3)$ & $2(2-3)$ & $2(2-3)$ \\
\hline HAS-BLED, median (IQR) & $0(0-1)$ & $0(0-1)$ & $0.5(0-1)$ & $0(0-1)$ \\
\hline Previous VKA, n (\%) & $7(37)$ & $9(17)$ & $8(36)$ & $24(26)$ \\
\hline Previous APT, n (\%) & $2(11)$ & $4(8)$ & $0(0)$ & $6(7)$ \\
\hline No previous therapy, n (\%) & $10(53 \%)$ & $39(75)$ & $14(64)$ & $63(68)$ \\
\hline \multicolumn{5}{|l|}{ NOAC therapy } \\
\hline Rivaroxaban, n (\%) & $9(47)$ & $21(40)$ & $10(45)$ & $40(43)$ \\
\hline Edoxaban, n (\%) & $3(16)$ & $14(27)$ & $5(23)$ & $22(24)$ \\
\hline Apixaban (\%) & $5(26)$ & $8(15)$ & $6(27)$ & $19(20)$ \\
\hline Dabigatran (\%) & $2(11)$ & $9(17)$ & $1(5)$ & $12(13)$ \\
\hline Full dose & $15(79)$ & $41(79)$ & $15(68)$ & $71(76)$ \\
\hline Reduced dose & $4(21)$ & $11(21)$ & $7(32)$ & $22(24)$ \\
\hline
\end{tabular}

The main diagnosis were atrial septal defect (20P, 21.5\%), tetralogy of Fallot (18P, 19.4\%), transposition of the great arteries (12P, 12.9\%), Ebstein's anomaly (9P, 9.7\%), ventricular septal defect (8P, 8.6\%), pulmonary stenosis (8P, 8.6\%), ductus arteriosus (5P, 5.4\%), atrioventricular septal defect, (4P, 4.3\%), univentricular heart (3P, 3.2\%), coarctation of the aorta (3P, 3.2\%), supra-aortic stenosis (2P, 2.2\%), truncus arteriosus $1 \mathrm{P}(1.1 \%)$ and Uhl's disease (1P, $1.1 \%)$ (Fig. 1). A total of 3 (3.2\%) patients had Fontan-type circulation (2 atrio-pulmonary connection and 1 TCPC) and 7 (7.5\%) patients had severe pulmonary vascular disease.

Most patients were anticoagulated with rivaroxaban (40P, 43\%), followed by edoxaban (22P, 24\%), apixaban (19P, 20\%) and dabigatran (12P, 13\%). 71P (76\%) were prescribed the standard dose and 22P (24\%) the reduced dose. Regarding previous anti-thrombotic therapy: 24 (25.8\%) were previously on VKA, 6 (6.5\%) on antiplatelet therapy and $63(67.7 \%)$ with no previous therapy.

The indications for oral anticoagulation were: prevention of thromboembolism secondary to atrial arrhythmias (75P, 81\%), predominantly atrial fibrillation (AF) (66P, 71\%), pulmonary embolism (PE) (6P, 6.3\%), atrial thrombi (4P, 4.3\%), thromboprophylaxis in Fontan circulation (3P, 3.2\%), deep vein thrombosis (3P, 3.2\%) and stroke $(2 \mathrm{P}, 2 \%)$.

Anemia (defined by a haemoglobin level of $<12.0 \mathrm{~g} / \mathrm{dL}$ in women and $<13.0 \mathrm{~g} / \mathrm{dL}$ in men) was present in 24 (25.8\%) and thrombocytopenia (defined as platelet count inferior to $150 \times 103$ per $\mu \mathrm{L}$ ) was present in $4(4.3 \%)$ patients. $66 \%$ of patients had a CHA囚DSヌ-VASc score of $\geq 2$ and $82 \%$ of patients had an 
HAS-BLED score of $\leq 2$ (Table 1).

In a mean follow-up of $41 \pm 21$ months (400.4 patient-years), there were thromboembolic events in two patients (2.2\%), one splenic infarction and one pulmonary embolism, a median time of 15.1 (IQR 5.1) months after initiation of NOAC therapy (Fig. 2). The annual risk for thromboembolism events was 0.49\%/patient/year. One patient (39 years old male) with an unrepaired PDA was under anticoagulation for an atrial thrombus, with a low CHA囚DS®-VASc score of 1 , suffered a splenic infarction, while other patient (79 years old female), with a repaired secundum ASD, under NOAC for AF, with a high CHA囚DS VASc score of 5 , suffered a pulmonary embolism. Both patients were under apixaban (the former patient with the standard dose, the latter with the adjusted reduced dose).

Bleeding events occurred in 9 patients (9.7\%), with major bleeding in 3 patients (3.1\%) and minor bleeding in 6 patients (6.5\%), a median time of 11.8 (IQR 14.5) months after starting NOAC therapy (Fig. 2). The annual risk for bleeding was $2.2 \%$ /patient/year. Patients with bleeding events had significantly higher serum creatinine levels $(1.12 \pm 0.46 \mathrm{mg} / \mathrm{dL}$ vs $0.87 \pm 0.21 \mathrm{mg} / \mathrm{dL}, \mathrm{p}=0.022)$, a higher HAS-BLED score (2 [IQR 1-3] vs 0.5 [IQR 0-1], p=0.001), and were most often taking the reduced NOAC dose ( $56 \%$ vs $20 \%, p=0.018)$. Anemia was more frequent in patients with bleeding events $(67 \%$ vs $21 \%, p=0.003)$. No difference was found regarding age ( $55 \pm 16$ vs $52 \pm 15, p=0.587)$, gender (female $78 \%$ vs $56 \%, p=0.207)$, CHA囚DS『-VASc score (2.5 [IQR 1-4] vs 2 [IQR 1-2], $p=0.001)$, concomitant antiplatelet therapy ( $11 \%$ vs $4 \%, \mathrm{p}=0.503)$, CHD severity or individual NOAC prescription (Table 2 ).

Table 2

Characteristics of ACHD patients with bleeding events versus patients without bleeding events

\begin{tabular}{|c|c|c|c|}
\hline & Bleeding events & No bleeding events & p-value \\
\hline$N(\%)$ & $9(10)$ & $84(90)$ & - \\
\hline Female gender, $\mathrm{n}(\%)$ & $7(78)$ & $47(56)$ & 0.207 \\
\hline Age (years) & $55 \pm 16$ & $52 \pm 15$ & 0.587 \\
\hline Mild CHD, n (\%) & $2(22)$ & $17(20)$ & 0.888 \\
\hline Moderate CHD, n (\%) & $5(56)$ & $47(56)$ & 0.982 \\
\hline Severe CHD, n (\%) & $2(22)$ & $20(24)$ & 0.915 \\
\hline Severe pulmonary hypertension, $\mathrm{n}(\%)$ & $1(11)$ & $6(7)$ & 0.668 \\
\hline BMI $\left(\mathrm{kg} / \mathrm{m}^{2}\right)$ & $23.3 \pm 4.4$ & $25.2 \pm 6.2$ & 0.253 \\
\hline Hypertension, n (\%) & $2(22)$ & $20(24)$ & 0.915 \\
\hline Diabetes, n (\%) & $1(11)$ & $5(6)$ & 0.549 \\
\hline Dyslipidaemia, n (\%) & $2(22)$ & $18(21)$ & 0.956 \\
\hline Smoker, n (\%) & $2(22)$ & $8(10)$ & 0.243 \\
\hline Anemia, n (\%) & $6(67)$ & $18(21)$ & 0.003 \\
\hline Mean serum creatinine $(\mathrm{mg} / \mathrm{dL})$ & $1.12 \pm 0.46$ & $0.87 \pm 0.21$ & 0.022 \\
\hline Concomitant APT, n (\%) & $1(11)$ & $3(4)$ & 0.503 \\
\hline CHA®DS®-VASc, median (IQR) & $2.5(1-4)$ & $2(1-2)$ & 0.217 \\
\hline HAS-BLED, median (IQR) & $2(1-3)$ & $0.5(0-1)$ & 0.001 \\
\hline NOAC therapy & Bleeding events & No bleeding events & \\
\hline Rivaroxaban, n (\%) & $3(33)$ & $37(44)$ & 0.537 \\
\hline Edoxaban, n (\%) & $3(33)$ & $19(23)$ & 0.472 \\
\hline Apixaban (\%) & $3(33)$ & $16(19)$ & 0.312 \\
\hline Dabigatran (\%) & $0(0)$ & $12(14)$ & 0.224 \\
\hline Reduced dose & $5(56)$ & $11(20)$ & 0.018 \\
\hline
\end{tabular}

The characteristics of the patients with thromboembolic and bleeding events are presented in Table 3. There were no thromboembolic or bleeding events in patients with Fontan-type circulation in our cohort. 
Table 3

Characteristics of patients with thromboembolic and bleeding events under NOAC therapy

\begin{tabular}{|c|c|c|c|c|c|c|c|c|c|c|c|c|}
\hline $\begin{array}{l}\text { Patient } \\
\text { No. }\end{array}$ & Gender & $\begin{array}{l}\text { Age } \\
\text { (v) }\end{array}$ & $\begin{array}{l}\text { CHD } \\
\text { diagnosis }\end{array}$ & $\begin{array}{l}\text { CHD } \\
\text { class }\end{array}$ & TE event & $\begin{array}{l}\text { Time to } \\
\text { TE } \\
\text { (months) }\end{array}$ & $\begin{array}{l}\text { Severe } \\
\mathrm{PH}\end{array}$ & Anemia & NOAC & Indication & $\begin{array}{l}\text { CHANDSX- } \\
\text { VASC }\end{array}$ & $\begin{array}{l}\text { HAS- } \\
\text { BLED }\end{array}$ \\
\hline 1 & Male & 39 & $\begin{array}{l}\text { Unrepaired } \\
\text { PDA }\end{array}$ & Moderate & $\begin{array}{l}\text { Splenic } \\
\text { infarction }\end{array}$ & 9.9 & No & No & Apixaban & $\begin{array}{l}\text { Atrial } \\
\text { thrombus }\end{array}$ & 1 & 0 \\
\hline 2 & Female & 79 & $\begin{array}{l}\text { Repaired } \\
\text { secundum } \\
\text { ASD }\end{array}$ & Mild & $\begin{array}{l}\text { Pulmonary } \\
\text { embolism }\end{array}$ & 20.1 & No & Yes & Apixaban & $\mathrm{AF}$ & 5 & 3 \\
\hline $\begin{array}{l}\text { Patient } \\
\text { No. }\end{array}$ & Gender & $\begin{array}{l}\text { Age } \\
\text { (v) }\end{array}$ & $\begin{array}{l}\text { CHD } \\
\text { diagnosis }\end{array}$ & $\begin{array}{l}\text { CHD } \\
\text { class }\end{array}$ & $\begin{array}{l}\text { Bleeding } \\
\text { event }\end{array}$ & $\begin{array}{l}\text { Time to } \\
\text { bleeding } \\
\text { (months) }\end{array}$ & $\begin{array}{l}\text { Severe } \\
\text { PH }\end{array}$ & Anemia & NOAC & Indication & $\begin{array}{l}\text { CHADS- } \\
\text { VASC }\end{array}$ & $\begin{array}{l}\text { HAS- } \\
\text { BLED }\end{array}$ \\
\hline \multicolumn{13}{|c|}{ Major bleeding } \\
\hline 1 & Female & 48 & $\begin{array}{l}\text { Unrepaired } \\
\text { PDA }\end{array}$ & Moderate & $\begin{array}{l}\text { Severe } \\
\text { hemoptysis }\end{array}$ & 6.8 & No & Yes & Apixaban & $\mathrm{PE}$ & 2 & 3 \\
\hline 2 & Female & 77 & $\begin{array}{l}\text { Unrepaired } \\
\text { ASD - } \\
\text { severe PH }\end{array}$ & Severe & $\begin{array}{l}\text { Esophageal } \\
\text { varices } \\
\text { rupture }\end{array}$ & 13.3 & Yes & No & Apixaban & AF & 4 & 3 \\
\hline 3 & Male & 42 & Ebstein & Moderate & $\begin{array}{l}\text { Severe } \\
\text { pericardial } \\
\text { effusion }\end{array}$ & 6.1 & No & Yes & Rivaroxaban & $\begin{array}{l}\text { Atrial } \\
\text { flutter }\end{array}$ & 1 & 1 \\
\hline \multicolumn{13}{|c|}{ Minor bleeding } \\
\hline 4 & Female & 42 & $\begin{array}{l}\text { Repaired } \\
\text { ToF }\end{array}$ & Moderate & $\begin{array}{l}\text { Oral } \\
\text { bleeding }\end{array}$ & 7.0 & No & No & Edoxaban & $\mathrm{AF}$ & 2 & 1 \\
\hline 5 & Female & 79 & $\begin{array}{l}\text { Repaired } \\
\text { ASD }\end{array}$ & Mild & $\begin{array}{l}\text { Mild GI } \\
\text { bleeding }\end{array}$ & 55.0 & No & Yes & Apixaban & $\mathrm{AF}$ & 5 & 3 \\
\hline 6 & Female & 61 & $\begin{array}{l}\text { Unrepaired } \\
\text { ASD }\end{array}$ & Moderate & $\begin{array}{l}\text { Mild GI } \\
\text { bleeding }\end{array}$ & 24.9 & No & Yes & Rivaroxaban & PE & 2 & 2 \\
\hline 7 & Female & 49 & $\begin{array}{l}\text { Repaired } \\
\text { ASD }\end{array}$ & Mild & Metrorrhagia & 3.1 & No & Yes & Edoxaban & $\begin{array}{l}\text { Atrial } \\
\text { flutter }\end{array}$ & 3 & 2 \\
\hline 8 & Female & 32 & $\begin{array}{l}\text { TGA, atrial } \\
\text { switch }\end{array}$ & Severe & Metrorrhagia & 11.8 & No & Yes & Rivaroxaban & PE & 1 & 1 \\
\hline 9 & Male & 63 & $\begin{array}{l}\text { Moderate } \\
\text { PS, ASD }\end{array}$ & Moderate & Hematuria & 16.9 & No & No & Edoxaban & AF & 2 & 0 \\
\hline
\end{tabular}

In the presented follow-up, the cardiovascular mortality was $2.2 \%$ ( 2 patients), with an annual rate of $0.5 \%$ /patient/year and the all-cause mortality was $5.4 \%$ ( 5 patients) with an annual rate of $1.2 \% /$ patient/year. There was no relation between mortality and thromboembolic or bleeding events.

In our cohort of ACHD patients, 8P (8.6\%) required NOAC dose adjustment to the reduced dose, mostly due to bleeding events on standard dose (3P, $3.2 \%$ ) or renal impairment (2P, 2.2\%). 10 patients (10.8\%) were switched to a different NOAC during follow-up, in the majority of cases to apixaban (6P, $6.4 \%)$ - due to worsening of renal function, bleeding events or dyspepsia with the previous NOAC - followed by edoxaban (2P, $2.2 \%)$ and dabigatran (2P, $2.2 \%)$. 7 patients (7.5\%) were switched to VKA, mostly due to mechanical prosthetic valve implantation (3P, 3.2\%), followed by bleeding events under NOAC (3P, 3.2\%) and diagnosis of antiphospholipid syndrome (1P, 1.1\%). In 6 patients (6.5\%), oral anticoagulation was suspended, mostly due to withdrawal of indication for anticoagulation (2P [2.2\%] with mild CHD due to CHA囚DS『-VASc score of $0,1 \mathrm{P}[1.1 \%]$ with no AF recurrence after catheter ablation), due to severe anemia (2P, $2.2 \%)$ or due to severe bleeding complications $1 \mathrm{P}(1.1 \%)$.

The univariate and multivariate regression analysis for bleeding events are presented in Table 4. The elevation of creatinine levels due to renal disease was a strong risk factor for major bleeding (HR 14.6 [95\% Cl 1.23 to 173.6], $p=0.033$ ). Multivariate analysis showed than an increased HAS-BLED score was a predictor of major (adjusted HR 6.97 [95\% Cl 1.69-28.78], p=0.007) and minor (adjusted HR 3.80 [95\% Cl 1.48-9.78], p=0.006) bleeding events, independently of age, gender and CHD severity. The CHA囚DS囚-VASc score and CHD severity were not correlated with bleeding events. 
Table 4

Univariable and multivariable regression analyses for bleeding events and major bleeding

\begin{tabular}{|c|c|c|c|}
\hline \multicolumn{4}{|c|}{ Major bleeding - Univariable regression } \\
\hline Model & Hazard ratio & $95 \%$ confidence interval & $\mathrm{p}$-value \\
\hline Serum creatinine & 14.63 & 1.23 to 173.62 & 0.033 \\
\hline CHA®DS®-VASC & 1.65 & 0.88 to 3.09 & 0.119 \\
\hline HAS-BLED & 5.06 & 1.76 to 14.52 & 0.003 \\
\hline Mild CHD & 0.94 & 0.11 to 8.42 & 0.956 \\
\hline Moderate CHD & 0.91 & 0.15 to 5.48 & 0.914 \\
\hline Severe CHD & 1.26 & 0.14 to 11.45 & 0.841 \\
\hline \multicolumn{4}{|c|}{ Major bleeding - Multivariable regression } \\
\hline Model & Hazard ratio & $95 \%$ confidence interval & $\mathrm{p}$-value \\
\hline Serum creatinine & 22.91 & 0.72 to 726.31 & 0.076 \\
\hline $\mathrm{CHA \otimes DS} \bowtie-V A S c$ & 1.61 & 0.60 to 4.31 & 0.345 \\
\hline HAS-BLED & 6.97 & 1.69 to 28.78 & 0.007 \\
\hline Mild CHD & 0.85 & 0.09 to 7.97 & 0.850 \\
\hline Moderate CHD & 0.88 & 0.15 to 5.34 & 0.892 \\
\hline Severe CHD & 1.56 & 0.15 to 16.74 & 0.712 \\
\hline \multicolumn{4}{|c|}{ Minor bleeding - Univariable regression } \\
\hline Model & Hazard ratio & $95 \%$ confidence interval & p-value \\
\hline Serum creatinine & 4.10 & 0.28 to 61.11 & 0.305 \\
\hline $\mathrm{CHA} \triangle \mathrm{DS} \bowtie-V A S c$ & 1.44 & 0.82 to 2.53 & 0.209 \\
\hline HAS-BLED & 2.83 & 1.32 to 6.05 & 0.007 \\
\hline Mild CHD & 1.79 & 0.33 to 9.79 & 0.503 \\
\hline Moderate CHD & 0.66 & 0.13 to 3.30 & 0.613 \\
\hline Severe CHD & 0.91 & 0.11 to 7.90 & 0.933 \\
\hline \multicolumn{4}{|c|}{ Minor bleeding - Multivariable regression } \\
\hline Model & Hazard ratio & $95 \%$ confidence interval & $\mathrm{p}$-value \\
\hline Serum creatinine & 5.93 & 0.33 to 107.56 & 0.229 \\
\hline $\mathrm{CHA} \triangle \mathrm{DS} \rrbracket-V A S c$ & 1.59 & 0.69 to 3.67 & 0.280 \\
\hline HAS-BLED & 3.80 & 1.48 to 9.78 & 0.006 \\
\hline Mild CHD & 1.87 & 0.33 to 10.62 & 0.482 \\
\hline Moderate CHD & 0.70 & 0.14 to 3.55 & 0.663 \\
\hline Severe CHD & 0.79 & 0.08 to 7.55 & 0.840 \\
\hline
\end{tabular}

\subsection{Discussion}

NOACs prescription in ACHD is constantly increasing, accounting for more than $40 \%$ of all oral anticoagulant prescriptions in a recent Germany nationwide study [2].

While the most robust evidence of NOACs safety and efficacy stems from randomized controlled trials in acquired heart disease, extrapolating directly from acquired to congenital cardiovascular conditions can be doubtful, due to differences in anatomy and physiology, aetiology and nature of arrhythmias and prothrombotic conditions $[3,13]$.

As previous demonstrated, in our cohort the main indication for anticoagulation was prevention of thromboembolism secondary to atrial arrhythmias [13]. Our results are reassuring showing that oral anticoagulation with NOACs is a safe and effective option for selected ACHD patients, with only two patients (2.2\%) suffering thromboembolic events during a medium follow-up of more than 3 years. 
Though our low thrombotic event rate could be explained by a younger age and more favourable cardiovascular risk profile comparing to acquired conditions, $66 \%$ of our population had actually a $\mathrm{CHA}_{2} \mathrm{DS}_{2}$-VASc score of $\geq 2$, and patients with thrombotic events did not have a significantly different CHA2DS2-VASc score (median 3 [IQR 2-4) comparing to patients with no events.

Due to a low rate of ischemic events, we did not search for thromboembolic predictors. It is still unclear whether $\mathrm{CHA}_{2} \mathrm{DS} \mathrm{S}_{2}-\mathrm{VASc} s c o r e$ is useful to estimate the risk of thromboembolic events in ACHD, with contradicting results in previous studies $[3,7]$. Most likely, thromboembolic risk is multifactorial in nature in ACHD patients, influenced more by the complexity of the CHD, presence of cyanosis, repair status, prosthetic material, and residual lesions than for traditional risk factors and age [7-9]. All these factors should be address in the creation of a future ACHD-CHADS specific score.

On the other hand, the annual risk of bleeding was $2.2 \%$ /patient/year in our cohort. Although not a negligible risk, particularly in patients with renal disease, in ACHD patients the bleeding risk under VKA has been previous estimated to be $4.4 \% / y e a r[7]$. In our cohort, HAS-BLED score was, in multivariate analysis, an independent predictor for major (adjusted HR 6.97) and minor bleedings (adjusted HR 3.80). We did not observe differences regarding the age, gender or complexity of the ACHD in patients with haemorrhagic events. Our study confirms the results from previous observational studies that showed HAS-BLED

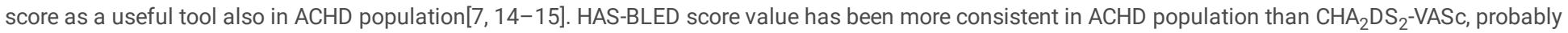
because it considers common issues in complex diseases, as in Fontan patients, namely renal and liver disease, and lability of the International Normalized Ratio (INR) [16].

Moreover, and as already demonstrated in studies with acquired disease and ACHD, renal disease showed to be a strong risk factor for bleeding in our population [15]. Indeed, in the study of Pujol C. et al with more than $200 \mathrm{ACHD}$ patients, renal disease was an independent predictor for bleeding (HR 6.13) in multivariate analysis, and the only risk factor found for major bleedings [15]. These findings reinforce the importance of dose adjustment according to renal function, which was the case in $2.2 \%$ of our cohort. However, one of the main reasons to switch to a different NOAC was related to the lower renal excretion of some NOACs compared to others, namely apixaban (in $6.4 \%$ of patients). Notably, over half (56\%) the patients in our cohort that had haemorrhagic events were already prescribed the adjusted reduced dose $(24 \%)$.

It is suggested that the requirement for regular laboratory monitoring and simultaneous contact with health care professionals may increase therapy adherence and reduce complication rates in VKA treated patients [2]. However, our hospital developed an Anticoagulation Outpatient Clinic that also include patients treated with NOACs, for switching from AVK to NOAC or for patients that require periodical laboratory testing due to renal impairment. In our experience, this approach can enhance patient education and reinforcement of appropriate compliance. Nevertheless, a study from the NOTE registry showed a good adherence (80-93\%) to NOAC during 2 years follow-up and a significant improvement in quality of life in patients with previous VKA therapy [9]. Longterm adherence to treatment is likely to translate into a lower thromboembolic event rate, especially in young patients who may need anticoagulation for decades [8].

Other important finding was in our ACHD unit-followed population the all-cause and cardiovascular mortality were unrelated to embolic or bleeding events, although we have not made comparisons with patients under VKA. In a nationwide German study, with majority of patients with simple lesions and many of them followed in non-tertiary ACHD centers, the authors found a significantly increased in the risk of MACE (HR 1.2) and all-cause mortality (HR 1.4) in the NOAC cohort compared with VKA patients, although the risk for major bleedings and thromboembolic events was similar [2]. These findings highlight the need for decisions in NOAC initiation be preferably made by cardiologists with CHD expertise, using an individual approach.

We admit that some subgroups were underrepresented in our cohort. We only included 3 patients with Fontan circulation, but neither major bleeding nor thrombotic complications occurred in this subgroup. Fontan patients appear to have a higher event rate (embolic and haemorrhagic) than the remainder [9], even though a study from NOTE registry showed NOACs were well tolerated, with comparable efficacy and safety during short-term follow-up to VKAs [5]. Although increasing evidence are emerging, Fontan population remain an important subgroup in whom further data are required to draw definitive conclusions [9].

The choice of oral anticoagulant must balance risks, benefits, comorbidities, namely renal disease, CHD complexity and patient expectations in relation to underlying CHD. Our results suggest that HAS-BLED score should be considered when balancing the risks of thromboprophylaxis in ACHD patients.

\subsubsection{Limitations}

This study is limited by its modest sample size, low event rate, relatively short follow-up and observational, retrospective and single center design. Notably, only a small number of patients with Fontan circulation were included. Also, the rate of thromboembolism may be underestimated as we did not routinely screen asymptomatic patients for subclinical thromboembolism.

\subsection{Conclusions}

NOACS appear to show evidence of efficacy and safety in ACHD patients with regular follow-up in a tertiary ACHD single center, in line with data from large multicenter evidence such as the NOTE registry [9]. Bleeding complications were not negligible, especially in patients with renal disease or a high HAS-BLED score. Patient selection is crucial, as initiation of NOACs in this heterogenous population should be individualized considering complexity, physiology and comorbidities, and further evidence is necessary for patients with complex ACHD, particularly Fontan patients.

\section{Abbreviations}

ACHD: Adult congenital heart disease 
AF: Atrial fibrillation

BAV: Bicuspid aortic valve

CT: Computerized tomography

ESC: European Society of Cardiology

NOAC: Non-vitamin K antagonist oral anticoagulants

PE: Pulmonary embolism

VKA: Vitamin K antagonists

TCPC: Total cavopulmonary connection

TOF: Tetralogy of Fallot

TGA: Transposition of the great arteries

\section{Declarations}

Funding. The authors declare that no funds, grants, or other support were received during the preparation of this manuscript

Disclosures. The authors have no relevant financial or non-financial interests to disclose.

Author contributions. Original study idea by Ana Agapito and Lídia Sousa. All authors contributed to the study conception and design. Data collection and analysis were performed by Pedro Garcia Brás and Tânia Branco Mano. The first draft of the manuscript was written by Pedro Garcia Brás and all authors commented on previous versions of the manuscript. Critical revisions were performed by Lídia Sousa. All authors read and approved the final manuscript.

Ethics. Ethical approval was waived by the local Ethics Committee (Centro Hospitalar Universitário Lisboa Central) in view of the retrospective nature of the study (conducted on already available digital data, obtained for clinical purposes). This study was performed in accordance with the ethical standards in the 1964 Declaration of Helsinki.

Consent. All patients were contacted (via telephone) and verbal informed consent was obtained prior to collection of the digital data. In the case of deceased patients, a family member or legal representative was contacted for informed consent. This manuscript does not contain any individual person's data in any form (including any individual details, images or videos).

Data availability statement. The dataset generated during this study is currently not publicly shared as it contains detailed individual patient data, which would compromise patient privacy. The generated dataset is currently accessible to the Santa Marta Hospital, Centro Universitário Hospitalar de Lisboa Central's Adult Congenital Heart Disease Unit Team.

\section{References}

1. Ruff C, Giugliano R, Braunwald E, Hoffman E, Deenadayalu N, Ezekowitz M. Comparison of the efficacy and safety of new oral anticoagulants with warfarin in patients with atrial fibrillation: a meta-analysis of randomised trials. Lancet. 2014;383,(9921):955-962. doi:https://doi.org/10.1016/S01406736(13)62343-0

2. Freisinger E, Gerß J, Makowski L, et al. Current use and safety of novel oral anticoagulants in adults with congenital heart disease: results of a nationwide analysis including more than 44000 patients. Eur Hear J. 2020;Nov 14(41(43):):4168-4177. doi:10.1093/eurheartj/ehaa844

3. Jensen A, Idorn L, Nørager B, Vejlstrup N, Sondergaard L. Anticoagulation in adults with congenital heart disease: The who, the when and the how? Heart. 2015;Mar;101(6):424-429. doi:10.1136/heartjnl-2014-305576

4. Mekaj Y, Mekaj A, Duci S, Miftari E. New oral anticoagulants: their advantages and disadvantages compared with vitamin $\mathrm{K}$ antagonists in the prevention and treatment of patients with thromboembolic events. Ther Clin Risk Manag. 2015;Jun 24;11:967-977. doi:10.2147/TCRM.S84210

5. Yang H, Veldtman G, Bouma B, et al. Non-vitamin K antagonist oral anticoagulants in adults with a Fontan circulation: are they safe. Heart. 2019; Jun 3(6(1):e000985). doi:10.1136/openhrt-2018-000985

6. Almutairi A, Zhou L, Gellad W, et al. Effectiveness and Safety of Non-vitamin K Antagonist Oral Anticoagulants for Atrial Fibrillation and Venous Thromboembolism: A Systematic Review and Meta-analyses. Clin Ther. 2017;Jul;39(7):1456-1478. doi:10.1016/j.clinthera.2017.05.358

7. Khairy P, Aboulhosn J, Broberg C, et al. Anticoagulation Therapy in Congenital Heart Disease (TACTIC) investigators and the Alliance for Adult Research in Congenital Cardiology (AARCC). Thromboprophylaxis for atrial arrhythmias in congenital heart disease: A multicenter study. Int J Cardiol. 2016;Nov 15(223):729-735. doi:10.1016/j.ijcard.2016.08.223

8. Stalikas N, Doundoulakis I, Karagiannidis E, et al. Non-Vitamin K Oral Anticoagulants in Adults with Congenital Heart Disease: A Systematic Review. J Clin Med. 2020;Jun 9;9(6):1794. doi:10.3390/jcm9061794

9. Yang H, Bouma B, Dimopoulos K, et al. Non-vitamin K antagonist oral anticoagulants (NOACs) for thromboembolic prevention, are they safe in congenital heart disease? Results of a worldwide study. Int J Cardiol. 2020;Jan 15;299(299):123-130. doi:10.1016/j.ijcard.2019.06.014

Page 9/11 
10. Baumgartner H, De Backer J, Babu-Narayan S, et al. 2020 ESC Guidelines for the management of adult congenital heart disease: The Task Force for the management of adult congenital heart disease of the European Society of Cardiology (ESC). Eur Heart J. 2020;42(6):563-645.

11. Stout K, Daniels C, Aboulhosn J, et al. 2018 AHA/ACC Guideline for the Management of Adults With Congenital Heart Disease: A Report of the American College of Cardiology/American Heart Association Task Force on Clinical Practice Guidelines. Circulation. 2019;139(14):698-e800. doi:https://doi.org/10.1161/CIR.0000000000000603

12. Mongeon F, Macle L, Beauchesne L, et al. Non-Vitamin K Antagonist Oral Anticoagulants in Adult Congenital Heart Disease. Can J Cardiol. 2019;Dec;35(12):1686-1697. doi:10.1016/j.cjca.2019.06.022

13. Pujol C, Niesert A, Engelhardt A, et al. Usefulness of Direct Oral Anticoagulants in Adult Congenital Heart Disease. Am J Cardiol. 2016;Feb 1;117(3):450455. doi:10.1016/j.amjcard.2015.10.062

14. Heidendael J, Bokma J, de Groot J, Koolbergen D, Mulder B, Bouma B. Weighing the risks: Thrombotic and bleeding events in adults with atrial arrhythmias and congenital heart disease. Int J Cardiol. 2015;186:315-320. doi:10.1016/j.ijcard.2015.02.024

15. Pujol C, Müssigmann M, Schiele S, et al. Direct oral anticoagulants in adults with congenital heart disease - a single center study. Int J Cardiol. 2020;Feb 1(300):127-131. doi:10.1016/j.ijcard.2019.09.077

16. Georgekutty J, Kazerouninia A, Wang Y, et al. Novel oral anticoagulant use in adult Fontan patients: A single center experience. Congenit Hear Dis. 2018;Jul;13(3):541-547. doi:10.1111/chd.12603

\section{Figures}

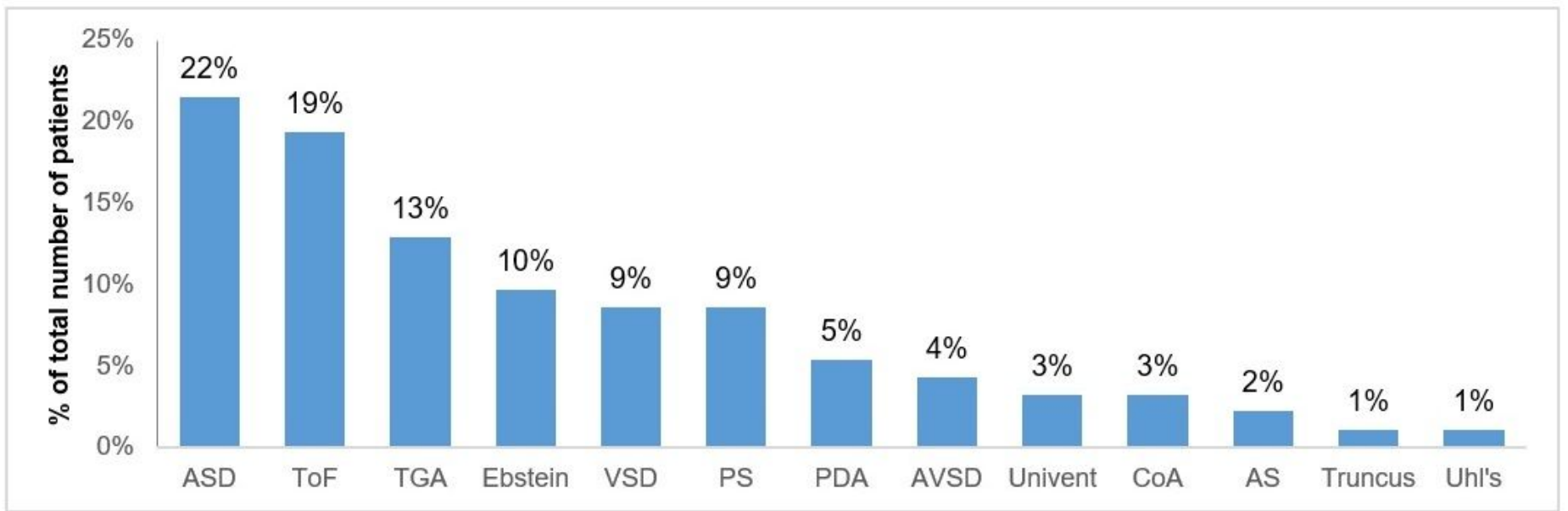

ASD: atrial septal defect; ToF: tetralogy of fallot, TGA: transposition of the great arteries;

VSD: ventricular septal defect; PS: pulmonary stenosis; PDA: patent ductus arteriosus;

AVSD: atrioventricular septal defect; Univent: univentricular heart, CoA: coarctation of the aorta;

AS: aortic stenosis; Truncus: truncus arteriosus

Figure 1

Caption not included with this version. 


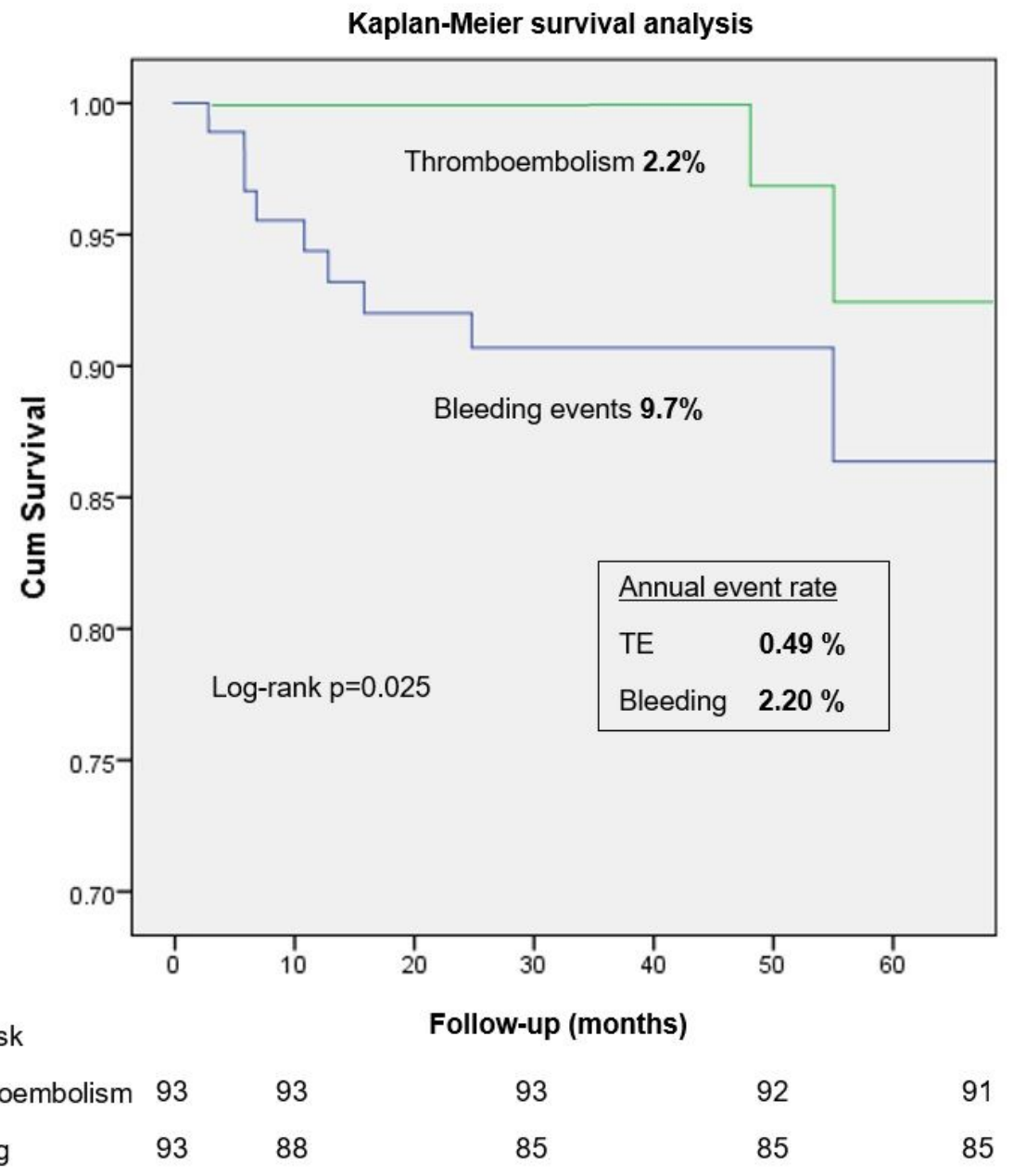

Figure 2

Caption not included with this version. 